\title{
Atendimento médico em automobilismo - uma nova perspectiva de trabalho
}

\author{
Medicine in motor sport - a new perspective of work
}

\author{
Dino Antonio Oswaldo Altmann
}

\begin{abstract}
Altmann DAO. Atendimento médico em automobilismo - uma nova perspectiva de trabalho/ Medicine in motor sport - a new perspective of work. Rev Med (São Paulo). 2012 jan.-mar.;91(1):28-33.

RESUMO: O atendimento médico em provas automobilísticas é uma atividade que passou a ser sistematizada após a morte de Ronnie Peterson ocorrida após seu acidente durante o Grande Prêmio da Itália, no circuito de Monza, em 1978. Foram necessários 18 minutos para retirá-lo de seu carro e ele faleceu por causa de embolia gordurosa decorrente das fraturas em membros inferiores. A despeito de acidentes de grande magnitude com imagens aterrorizantes, não houve mais nenhuma morte de piloto na Fórmula 1 após os acidentes de Roland Ratzemberger e Ayrton Senna em 1994, graças à melhora das condições de segurança dos circuitos, carros e equipamentos dos pilotos.
\end{abstract}

DESCRITORES: Ferimentos e lesões; Cuidados médicos/recursos humanos.

atuação do médico no automobilismo, em caso de um acidente, se assemelha ao atendimento pré-hospitalar do trauma, porém tem suas particularidades estratégicas que permitem o primeiro atendimento após alguns segundos ou minutos. Porém, sua atuação não se resume ao atendimento ao trauma, mas também na prevenção de lesões mais importantes e das mortes. Para tanto, participa das ações preventivas relacionadas à segurança dos circuitos, construção dos carros e equipamentos pessoais dos pilotos. A reabilitação de um piloto é outra área em que o médico pode atuar.

Medidas de segurança do habitáculo do piloto, barreiras de proteção e configuração dos circuitos, tiveram grande impacto na redução do número de acidentes com vítimas fatais em provas automobilísticas.

Basicamente o atendimento médico ao piloto acidentado segue a padronização do atendimento ao politraumatizado desenvolvido nas grandes guerras, com o primeiro atendimento no campo de batalha, seguido do atendimento em uma unidade avançada que dá suporte em campo e uma unidade hospitalar de retaguarda, capacitada para o atendimento do trauma, onde o tratamento definitivo é realizado. O transporte do campo ao hospital de retaguarda teve seu tempo reduzido graças à utilização de helicópteros.

Doutor pelo Departamento de cirurgia da FMUSP. Membro da comissão médica da Federação Internacional de Automobilismo. Presidente da comissão médica da Confederação Brasileira de Automobilismo. Diretor médico do Grande Prêmio Brasil de Fórmula 1.

Endereço para correspondência: Rua Jesuino Arruda 676 conj. 131, Itaim Bibi, 04532-082 São Paulo, SP. e-mail: dino @ altmann.com. br 


\section{Infraestrutura médica durante o Grande Prêmio Brasil de Fórmula 1 (F1)}

A infraestrutura médica de um Grande Prêmio de F1 conta com o centro médico do circuito, unidades de atendimento em pista e duas unidades hospitalares de retaguarda para onde são removidos eventuais acidentados. A coordenação do atendimento está a cargo do diretor médico que a partir da sala controle, em conjunto com o diretor de prova, orienta a equipe em caso de acidente e toma as devidas providências necessárias para a remoção de uma vítima para o hospital de retaguarda. A comunicação entre o diretor médico e os demais membros da equipe é feita através de rádios de comunicação.

O centro médico do circuito é composto por uma sala de suporte avançado à vida e atendimento aos queimados com três leitos, unidade de terapia intensiva com dois leitos, ambulatório com cinco estações de atendimento e observação, consultório oftalmológico, raio- $X$, ultrassonografia e laboratório de análises clínicas.

A equipe médica é composta por profissionais experientes nas mais diversas especialidades, como cirurgia do trauma, neurologia, anestesia, terapia intensiva, ortopedia, cirurgia torácica, cirurgia plástica e queimaduras, cardiologia e oftalmologia.

Enfermeiras com especialização nas áreas específicas dão apoio à equipe médica.

\section{Unidades de atendimento em pista}

O atendimento deve ser ágil, preciso e seguro. Para tanto, os médicos envolvidos recebem treinamento específico, padronizado pela FIA e seguem o modelo descrito no livro "Medicine in Motor Sport" publicado pelo Instituto $\mathrm{FIA}^{1}$. As equipes são divididas entre os veículos de intervenção médica, veículos de extração e ambulâncias que ficam dispostos em pista de tal forma que possam chegar rapidamente a qualquer ponto.

Os veículos de intervenção médica são conduzidos por pilotos profissionais e sua equipe composta por dois médicos e um oficial de desencarceramento. São equipados com material médico de emergência para imobilizações, vias aéreas, acesso venoso e reanimação cardiorrespiratória.

Os veículos de extração também são conduzidos por pilotos profissionais e sua equipe composta por dois médicos e quatro paramédicos treinados para imobilização e extração de um piloto que necessite auxílio para sair do carro. Contam ainda com dois especialistas em desencarceramento. São equipados com material de imobilização e também com ferramentas de desencarceramento.
As ambulâncias têm sua equipe composta por médico, enfermeiro e paramédico e são equipadas para o suporte avançado de vida. Tem como objetivo o transporte de um acidentado do local do acidente ao centro médico e eventualmente para o hospital de retaguarda.

\section{Dinâmica de atendimento em automobilismo}

Em caso de acidente, o diretor médico aciona e dirige cada uma das unidades de pista, depois que o diretor de prova tenha tomado as medidas necessárias para a segurança dos demais competidores e equipe médica. Estas medidas são representadas pela sinalização com bandeiras e liberação do veículo de segurança (Safety Car) para neutralização da prova.

Os primeiros a chegarem ao local do acidente são os veículos de intervenção rápida, seguidos pelos veículos de extração e ambulâncias, quando necessários.

Os médicos dos veículos de intervenção rápida são responsáveis pelo atendimento inicial ao traumatizado e orientam a equipe de extração quanto à melhor forma de retirar o piloto do carro em função da gravidade de sua condição clínica. A extração rápida utiliza uma prancha longa de imobilização nos casos de maior gravidade, enquanto que a retirada do piloto imobilizado no próprio assento removível ou com KED (Kendrik Extrication Device) é reservada para pacientes em condições clínicas estáveis.

As ambulâncias são utilizadas para o transporte da vítima ao centro médico. Durante este transporte a avaliação inicial é refeita e os procedimentos necessários realizados à medida que são diagnosticados.

No centro médico, o paciente é submetido à avaliação secundária e estabilizado para o transporte, com helicóptero aeromédico para o hospital de trauma de referência.

No automobilismo, o socorro a um acidentado é bastante peculiar em virtude do tempo reduzido que as equipes médicas levam para chegar ao local do acidente, com uma competição ainda em andamento. Esta situação trás riscos adicionais para a equipe médica, que deve ter em mente sua própria segurança e também gera condições adversas para o atendimento, representadas principalmente pelo nível de ruído que muitas vezes impede a ausculta do paciente. $O$ tempo reduzido da chegada da equipe ao local do acidente faz com que a equipe possa ainda encontrar com vida um acidentado cujo destino já está definido pela gravidade das lesões geradas pelo impacto ou mesmo encontrar um piloto não responsivo que logo a seguir está conversando.

Pacientes vítimas de trauma que recebem o 
tratamento definitivo, na maioria das vezes representado pelo controle de hemorragias na sala de operações na primeira hora após um acidente, têm maior possibilidade de sobrevida do que aqueles que o recebem mais tarde. Assim, a maior responsabilidade dos médicos de pista é gastar o menor tempo possível no local do acidente, realizando somente os procedimentos absolutamente necessários para salvar a vida e preparando o paciente para o transporte até o hospital de retaguarda que deve estar devidamente preparado para recebê-lo.

O fator mais crítico para qualquer vítima de trauma é o tempo decorrido entre o acidente e o tratamento definitivo. A expectativa é que o atendimento em pista não demore mais do que dez ou quinze minutos e que o mesmo tempo seja gasto no centro médico. O transporte aeromédico não vai durar mais do que dez minutos e assim a "hora de ouro" do paciente politraumatizado estará sendo respeitada.

\section{Avaliação inicial ao piloto traumatizado}

A avaliação inicial se inicia com a observação da condição geral do piloto, englobando respiração, circulação e condições neurológicas para identificação de problemas com oxigenação, circulação, hemorragias ou deformidades. Em poucos segundos esta avaliação pode ser realizada, com a simples abertura do visor do capacete e a realização de perguntas simples ao piloto. A resposta verbal apropriada indica a ausência do comprometimento do sistema respiratório e uma adequada perfusão cerebral. A queixa de dor e sua localização é uma informação importante nos cuidados subsequentes. A cabeça e o pescoço do piloto devem ser imobilizados manualmente e desde que hajam duas pessoas treinadas presentes, o capacete e o dispositivo de proteção da coluna cervical (HANS - Head and Neck Support) podem ser removidos neste momento.

\section{A - Vias aéreas e estabilização da coluna cervical}

O médico de pista deve rapidamente verificar se a via aérea está pérvia e assegurar que nenhum perigo de obstrução existe. Uma vítima não responsiva deve ser encarada como se tivesse a via aérea comprometida em razão da diminuição de seus reflexos de proteção. Inabilidade para falar, taquipnéia, rouquidão e outros ruídos são sinais de obstrução das vias aéreas.

Esta fase do atendimento primário não pode ser considerada completa enquanto não existir a segurança de que a via aérea está desobstruída e sua permeabilidade segura, pelo menos até a chegada do paciente ao centro médico. A sucção de secreções e manobras avançadas para a permeabilização das vias aéreas podem ser necessárias, bem como o suporte ventilatório que deve incluir a administração de altas concentrações de oxigênio.

Todo piloto, cujo mecanismo de trauma envolveu alta energia, é suspeito de ter lesão da coluna cervical e precisa ser considerado instável até que se prove o contrário. A prova de que nenhuma lesão cervical existe, muitas vezes só vais ser obtida mais tarde, com a realização de exames complementares no hospital de referência. Felizmente, as medidas de segurança introduzidas nos últimos anos tem reduzido de forma importante as lesões cervicais. Porém, esta continua sendo uma preocupação constante para o médico que atua no automobilismo.

Para estabelecer a permeabilidade da via aérea, o médico de pista deve saber que todas as intervenções causam algum movimento da coluna cervical e que este é um tópico de contínua discussão por causa da falta de dados e respostas incompletas sobre qual a melhor maneira de minimizar os riscos de lesões neurológicas adicionais.

A incidência de lesões da coluna cervical está aumentada quando existe a associação de lesão do Sistema Nervoso Central e principalmente se o nível da escala de Glasgow for inferior a 8 ou se existe deficiência neurológica focal.

O comprometimento neurológico primário está relacionado às forças de cisalhamento, compressão, distensão ou penetração de corpo estranho, como fragmento ósseo. A lesão secundária e progressiva resulta da falta de imobilização da coluna cervical em posição neutra, hipotensão arterial sistêmica, hipoventilação ou aumento da pressão da veia cava secundária ao pneumotórax hipertensivo ou tamponamento pericárdico.

A utilização do colar cervical e imobilização da vítima em uma prancha longa com blocos que fixam a cabeça consistem na forma mais usual de extração e transporte no atendimento pré-hospitalar do trauma. O colar cervical reduz significativamente a abertura da boca e pode interferir com os procedimentos das vias aéreas. Desta forma, a liberação do colar cervical com a imobilização manual em linha da coluna cervical é necessária durante a intervenção médica. A imobilização cervical em linha é eficiente em reduzir o movimento da coluna como um todo, mas é preciso lembrar que ela é menos restritiva no local da lesão.

Manobras básicas, como a máscara de ventilação, causam maior movimentação cervical do que outros procedimentos avançados. Causam movimento comparável a entubação orotraqueal com laringoscópio e diferentes tipos de lâminas com o Glidescope $₫$, 
inserção da máscara laríngea, Combitube $\AA$ ou a cânula faringotraqueal. Também existe movimento comparável durante a entubação nasotraqueal e mesmo durante a cricotireoidotomia. A entubação orotraqueal com auxílio de fibroscópio flexível parece resultar em menor movimento da coluna cervical do que a observada com outros métodos².

Não há na literatura dados que sugiram melhor resultado neurológico com qualquer um dos métodos mencionados. A ventilação com máscara deveria ser evitada. É muito importante que se imobilize a coluna cervical de maneira correta durante os procedimentos nas vias aéreas e também vale lembrar que más condições clínicas contribuem para a lesão medular secundária e progressiva. Criar seu próprio algoritmo a ser seguido em casos onde há suspeita de lesão cervical é importante.

A imobilização precoce e eficaz da coluna como um todo é o princípio mais importante do atendimento, até que uma lesão possa ser definitivamente excluída.

$\mathrm{Na}$ eventualidade de um piloto estar preso às ferragens do veículo, o médico de pista deve remover o capacete e o HANS e colocar colar cervical e uma máscara de oxigênio na face do piloto. A imobilização manual em linha da coluna cervical completa a estabilização da coluna enquanto se espera a equipe de extração para remover o piloto das ferragens. Outros procedimentos em vias aéreas podem ser necessários, porém são extremamente difíceis nestas circunstâncias. Após controlar a vias aéreas e respiração, o médico de pista deve inserir um acesso venoso periférico de grande calibre, enquanto espera a equipe de extração realizar seu trabalho.

\section{B - Respiração}

Quando a via aérea da vítima estiver permeável e segura, a respiração pode ser avaliada.

A avaliação da respiração começa quando o médico inicialmente fala com o piloto. Um piloto que não responde deve ser considerado como se tivesse um comprometimento respiratório, bem como de vias aéreas.

A taquipnéia não deve, pelo menos inicialmente, ser interpretada como compensatória. Assumir que ela está relacionada a um problema respiratório é mais seguro. A incapacidade de falar sentenças completas deve indicar um comprometimento respiratório mais importante.

Percussão e ausculta torácica estão limitadas de maneira importante pelo barulho durante o atendimento em pista. Desta forma, a percepção clínica, um alto índice de suspeita e a atenção ao mecanismo de trauma, vão orientar o médico de pista nesta fase de avaliação e procedimentos. A oximetria de pulso pode ser de grande valor nesta fase da avaliação.

Se a ventilação é adequada, a vítima deve receber suplementação de oxigênio, que de uma forma ideal é oferecido através de uma máscara com válvula que impede a reinalação e com alto fluxo (12 a $15 \mathrm{l} /$ min). A ventilação assistida é necessária quando o piloto não está respirando espontaneamente.

A parada respiratória transitória é frequente quando existe um traumatismo craneoencefálico e pode ser uma causa de morte na cena do acidente. A entubação endotraqueal destes pacientes é o aspecto mais importante no atendimento e deve ser realizada sem perda de tempo.

A imediata ameaça à vida encontrada nesta fase do atendimento primário é o pneumotórax hipertensivo ou aberto. Do ponto de vista prático, importante dispneia pode ser observada após um acidente como resultante de dor e não necessariamente respiração paradoxal após fraturas de arcos costais.

\section{C - Circulação e sangramento}

Antes desta fase do atendimento, salvo excepcional circunstância, deve-se pensar em iniciar o transporte do piloto para o centro médico, enquanto a avaliação da circulação e possíveis sangramentos podem ser realizados na ambulância, rumo ao centro médico.

Os objetivos da avaliação circulatória primária são: verificar se o paciente está em choque e identificar sangramentos externos.

O diagnóstico de choque é eminentemente clínico através de sinais de má perfusão e mecanismos compensatórios. Vale lembrar que os pilotos profissionais são extremamente bem preparados fisicamente e que sua capacidade de compensar perdas volumétricas agudas é grande.

$\mathrm{Na}$ grande maioria dos casos, o choque é secundário ao sangramento e mesmo que outras causas possam ocorrer, a infusão de fluidos é útil em todas as etiologias de choque traumático.

A menos que haja um sangramento maciço e extremamente rápido, o choque não vai se tornar aparente nesta fase do atendimento primário, em razão da rapidez do atendimento médico observado no automobilismo. Por isso, apesar da avaliação clínica ser mandatória, a observação do mecanismo de trauma, o instinto clínico e um alto índice de suspeita deve ser considerado enquanto se avalia o paciente.

A taquicardia é uma constante, quando se avalia um piloto acidentado, em função da atividade que está exercendo, bem como da elevada temperatura dentro dos carros fechados. A qualidade do pulso é 
mais importante nestas situações. Também devemos lembrar que a sudorese está sempre presente, mas a pele estará quente ao toque, diferenciando da pele fria, pastosa e úmida do paciente em choque.

O sangramento externo deve ser controlado assim que possível, através da compressão direta do local do sangramento, elevação da extremidade ou compressão proximal da artéria que irriga a região do sangramento. Os torniquetes são a última alternativa a ser empregada, porém podem ser de grande valia em casos de amputação traumática de um membro.

A inserção de dois acessos venosos periféricos de grosso calibre é mandatória na presença de choque ou grande hemorragia externa. A reposição volêmica deve ser iniciada com soluções cristaloides. O conceito de hipotensão permissiva e retardo na reposição volêmica tem sido mais aceito ${ }^{3}$. Se existe comprometimento do sistema nervoso central, a pressão sistólica deve ser mantida em torno de 100 $\mathrm{mmHg}$. Se a condição de choque é secundária ao sangramento interno, o médico de pista não deve perder tempo. A rápida remoção para o centro médico e dali para o hospital de trauma de referência, resultam na maior possibilidade de controle da hemorragia, antes que hipotermia, acidose e distúrbios de coagulação se instalem. No hospital de referência, sangue estará disponível e a volemia do paciente pode ser plenamente reestabelecida na sala de cirurgia, após controle da hemorragia.

\section{D - Incapacidade}

Após a avaliação e os procedimentos de $A B C$, o médico deve avaliar a condição neurológica do paciente. Mais uma vez isto é feito na ambulância a caminho do centro médico.

Um paciente agressivo, combativo e não cooperante deve ser considerado hipóxico ou com hipofluxo cerebral, até prova em contrário. O médico de pista deve procurar saber se o piloto perdeu a consciência em algum momento, após o acidente.

Durante a avaliação primária, a condição neurológica pode ser avaliada pelo exame das pupilas e a determinação do estado de consciência. Isto pode ser feito utilizando-se a Escala de Coma de Glasgow. O médico de pista deve determinar o valor da Escala de Coma de Glasgow e incluí-lo no relatório verbal a ser transmitido para o centro médico.

Um valor de Glasgow abaixo de 8 é indicativo de entubação do paciente, por causa da necessidade de se otimizar o aporte de oxigênio e ventilação para proteger o sistema nervoso central traumatizado e também porque neste nível de coma os reflexos laríngeos protetores não estão presentes. $\mathrm{A}$ entu- bação ainda em pista por causa da gravidade da lesão encefálica, quase sempre necessita da indução anestésica (sequência rápida). Após controle da via aérea e revisão dos elementos da avaliação primária, o paciente deve ser rapidamente transferido para o centro médico.

Após a avaliação das incapacidades, se não antes, dependendo das circunstâncias, o paciente deve ser transferido para o centro médico.

\section{E - Exposição / Ambiente}

Esta etapa da avaliação primária deve ser realizada no centro médico. A equipe médica deve expor e examinar o corpo inteiro a procura de lesões adicionais. Hipotermia é um problema importante durante a avaliação do paciente vítima de trauma e cobertores térmicos devem ser usados na sua prevenção.

\section{Parada cardiorespiratória traumática (PCRT)}

A parada cardiorespiratória resultante do trauma é quase sempre relacionada a exsanguinação ou com lesões incompatíveis com a vida, como as lesões encefálicas e medulares graves. A PCRT não pode ser adequadamente ressuscitada no local do acidente e quando possível o paciente deve ser transferido de helicóptero do local do acidente para o hospital de trauma de referência. É importante que o hospital de referência seja imediatamente comunicado para mobilizar recursos antes da chegada do paciente.

A PCRT tem péssimo prognóstico e menos do que $2,3 \%$ dos pacientes com parada cardiorrespiratória em razão de trauma fechado vão sobreviver. Apesar disso, no contexto do automobilismo, a decisão de não reanimar ou parar a reanimação no local do acidente não deve ser tomada. A revisão dos dados da literatura sugere que se o paciente chegar ao hospital de trauma de referência 20 minutos após a ocorrência do acidente, a mortalidade será de 100\%. O tempo é crítico e se a demora na cena do acidente for maior do que estes 20 minutos, este deve ser considerado um evento letal. A pequena porcentagem de pacientes que saem vivos do hospital vai apresentar deficiências neurológicas importantes ${ }^{4}$.

\section{Avaliação secundária}

Após completar a avaliação primária, com identificação e tratamento das lesões que colocam a vida em risco, a avaliação secundária se inicia no centro médico. Seu objetivo é identificar lesões ou problemas que não foram identificados durante a avaliação primária. Envolve a completa avaliação clínica do paciente, através do exame físico, anam- 
nese e exames auxiliares. É no centro médico, após a avaliação secundária, que a decisão de transferir o paciente para o hospital de referência será tomada. Uma vez no centro médico, o piloto acidentado deve ser, se assim se fizer necessário, monitorado com eletrocardiograma contínuo, oximetria de pulso, pressão arterial e com capnógrafio se estiver entubado. Adequada ressuscitação pode ser melhor empregada com a utilização de parâmetros fisiológicos como frequência de pulso, pressão arterial, oximetria, frequência respiratória, temperatura corpórea e débito urinário ${ }^{5}$. Análises sanguíneas podem ser realizadas quando disponíveis.

O preparo para o transporte do paciente para o hospital de trauma de referência deve ser iniciado assim que o paciente estiver monitorado e protegido da hipotermia. O paciente instável durante a avaliação primária tem urgência de ser transferido, enquanto mais tempo pode ser gasto para transferência do paciente estável, que pode receber cuidados a lesões individualizadas antes do transporte.

$\mathrm{Na}$ maioria das vezes, o tratamento definitivo do piloto acidentado em uma corrida de automóvel pode ser somente realizado na sala de cirurgia. Qualquer coisa que retarde o tratamento definitivo vai diminuir as chances de o piloto sobreviver, nos casos em que as lesões são graves. Os cuidados em pista e no centro médico somente o mantém com vida e em melhores condições fisiológicas para receber o tratamento definitivo. Por esta razão, os cuidados administrados no circuito devem somente tratar problemas que ameaçam a vida e proporcionar condição mais segura para o transporte. Facilitar o acesso ao tratamento definitivo é a atitude mais importante da equipe médica que está no circuito.

\section{REFERÊNCIAS}

1. Medicine in motor sport. FIA Institute; 2011. Available from: http://www.fiainstitute.com/ publications/Pages/home.aspx.

2. Crosby ET. Airway management in adults after cervical spine trauma. Anesthesiology. 2006;104:1293-318.

3. HolmesCL, Walley KR. The evaluation and management of shock. Clin Chest Med. 2003;24:775-89.

4. Hopson LR, Hirsh E, Delgado J, Domeier RM, McSwain Jr NE, Krohmer J. Guidelines for withholding or termination of resuscitation in prehospital traumatic cardiopulmonary arrest: joint position statement of the National Association of EMS Physicians and the American College of Surgeons Committeee on Trauma. J Am Coll Surg. 2003; 96:106-12.

5. Richards CF, Mayberry JC. Initial management of the trauma patient. Crit Care Med. 2004;20:111. 